\title{
From the Transcription of Genes Involved in Ectodermal Dysplasias to the Understanding of Associated Dental Anomalies
}

\author{
V. Laugel-Haushalter ${ }^{a} \quad$ A. Langer ${ }^{b} \quad$ J. Marrie $^{a} \quad$ V. Fraulob ${ }^{a} \quad$ B. Schuhbaur \\ M. Koch-Phillips ${ }^{a} \quad$ P. Dollé ${ }^{a} \quad$ A. Bloch-Zupan ${ }^{a-c}$

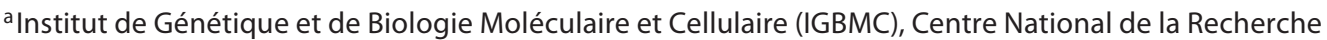 \\ Scientifique (UMR 7104), Institut National de la Santé et de la Recherche Médicale (U 964), Université de \\ Strasbourg, Illkirch, ${ }^{b}$ Faculty of Dentistry, University of Strasbourg, and ${ }^{\mathrm{C}}$ Reference Centre for Orodental \\ Manifestations of Rare Diseases, Pôle de Médecine et Chirurgie Bucco-Dentaires, Hôpitaux Universitaires de \\ Strasbourg (HUS), Strasbourg, France
}

\section{Key Words}

Dental anomalies $\cdot$ Ectodermal dysplasia $\cdot$ Gene

expression $\cdot$ Mouse $\cdot$ Tooth development

\begin{abstract}
Orodental anomalies are one aspect of rare diseases and are increasingly identified as diagnostic and predictive traits. To understand the rationale behind gene expression during tooth or other ectodermal derivative development and the disruption of odontogenesis or hair and salivary gland formation in human syndromes we analyzed the expression patterns of a set of genes (Irf6, Nfkbia, Ercc3, Evc2, Map2k1) involved in human ectodermal dysplasias in mouse by in situ hybridization. The expression patterns of Nfkbia, Ercc3 and Evc2 during odontogenesis had never been reported previously. All genes were indeed transcribed in different tissues/ organs of ectodermal origin. However, for Nfkbia, Ercc3, Evc2, and Map2k1, signals were also present in the ectomesenchymal components of the tooth germs. These expression patterns were consistent in timing and localization with the known dental anomalies (tooth agenesis, microdontia, conical shape, enamel hypoplasia) encountered in syndromes resulting from mutations in those genes. They could also explain the similar orodental anomalies encountered in some
\end{abstract}

of the corresponding mutant mouse models. Translational approaches in development and medicine are relevant to gain understanding of the molecular events underlying clinical manifestations.

Copyright $\odot 2012$ S. Karger AG, Basel

Oral cavity and dental developmental anomalies are one aspect of rare diseases or syndromes. These diseases, which encompass about 8,000 different entities, affect 4 million people in France and almost 25 millions in Europe. Per se and definition they affect less than a person among 2,000 and $80 \%$ of them are genetically driven. Among more than 7,000 known syndromes, at least 900 have a dento/oro/facial phenotype and 750 display in their clinical synopsis a cleft lip/palate. This is understandable as the same genes and signaling pathways regulate palate, tooth development and the organogenesis of other systems. Considering the dual origin of teeth (the oral ectoderm for the enamel organ and the derived ameloblasts synthesizing the enamel matrix, and ectomesenchyme originating from the cephalic neural crest cells for the mesenchymal part of the tooth including pulp tissues, odontoblasts and the periodontium), orodental anomalies are very often present in syndromes involving

\section{KARGER \\ Fax +4161306 1234 \\ E-Mail karger@karger.ch}

www.karger.com
(C) 2012 S. Karger AG, Basel

$1661-8769 / 12 / 0034-0158 \$ 38.00 / 0$

Accessible online at:

www.karger.com/msy
Agnès Bloch-Zupan

Institut de Génétique et de Biologie Moléculaire et Cellulaire (IGBMC) BP 10142

1 rue Laurent Fries, FR-67404 Illkirch Cedex (France)

E-Mail agnes.bloch-zupan@ unistra.fr 
ectodermal derivatives like ectodermal dysplasias (EDs) where abnormalities of tooth number (missing teeth), shape (conical crown, taurodontic molars) or hard tissue structures (enamel hypoplasia) are part of the phenotype. These anomalies, associated to the clinical synopsis of these syndromes are increasingly identified as diagnostic and predictive traits.

The aim of this study is to increase the knowledge of genes involved in tooth development and anomalies in a syndromic context within the group of EDs through the analysis of their expression patterns during mouse odontogenesis, as well as in other ectodermal organs like salivary glands and vibrissae. Using a bioinformatic approach, we selected known genes involved in EDs within online databases (Online Mendelian Inheritance in Man, Orphanet [Aymé et al., 1998; Aymé, 2003]) and the literature ([Gorlin et al., 2001; Hennekam et al., 2010], PubMed (http://www.ncbi.nlm.nih.gov/pubmed/)) with limited information about their expression pattern or role during odontogenesis. The online EURExpress in situ hybridization atlas (http://www.eurexpress.org; http://www.genepaint.org/) [Diez-Roux et al., 2011] was then used to identify genes showing detectable expression in tooth buds of embryonic day (E)14.5 mice. Five genes were thus selected, for which we performed a detailed analysis of their expression patterns by in situ hybridization at various stages of mouse development.

\section{Materials and Methods}

\section{Sample Preparation}

Mouse embryos/fetuses were collected at E12.5, E14.5, E16.5, and on the day of birth (hereafter referred to as E19.5), after natural matings between C57BL6 mice. For E14.5 and older samples, the whole head was embedded in OCT 4583 medium (TissueTEK, Sakura) and frozen on the surface of dry ice. E12.5 embryos were fixed overnight in $4 \%$ paraformaldehyde $(\mathrm{pH} 7.5, \mathrm{w} / \mathrm{v})$ in PBS, cryoprotected by overnight incubation in $20 \%$ sucrose $(\mathrm{w} / \mathrm{v})$ in PBS, and cryoembedded as described above. Cryosections (Leica CM3050S cryostat) at $10 \mu \mathrm{m}$ were collected on Superfrost plus slides and stored at $-80^{\circ} \mathrm{C}$ until hybridization. E12.5 and E14.5 samples were sectioned in a frontal plane, whereas other stages were sectioned sagittally.

\section{Probe Synthesis}

All probes were synthesized from PCR-generated DNA templates kindly provided by the EURExpress consortium (http:// www.eurexpress.org). The template sequences are given in online suppl. fig. 1 (www.karger.com/doi/10.1159/000342833).

DIG-labeled antisense riboprobes were transcribed in vitro by incubation for $2 \mathrm{~h}$ at $37^{\circ} \mathrm{C}$ using $1 \mu \mathrm{g}$ of the PCR product, $20 \mathrm{U}$ RNA polymerase, $5 \times$ transcription buffer (Promega), $10 \times$ DIG RNA labeling Mix (Roche), 0.5 M DTT, 20 U RNAse inhibitor
(Roche) in a $20-\mu l$ volume. The following RNA polymerases (Sigma) were used: T7 polymerase (Ercc3 and Evc2 probes), T3 polymerase (Irf6 and Map $2 k 1$ probes) and SP6 polymerase (Nfkbia probe). The reaction was stopped with $2 \mu$ I EDTA $(0.2 \mathrm{M}, \mathrm{pH} 8)$, and RNA was precipitated with $1 \mu$ l yeast tRNA $(10 \mathrm{mg} / \mathrm{ml}), 2.5$ $\mu \mathrm{LiCl}(4 \mathrm{M})$ and $75 \mu \mathrm{l}$ absolute ethanol, followed by an incubation for $30 \mathrm{~min}$ at $-80^{\circ} \mathrm{C}$ and centrifugation at $12,000 \mathrm{rpm}(30 \mathrm{~min}$ at $\left.4^{\circ} \mathrm{C}\right)$. The pellet was washed with $0.5 \mathrm{ml}$ ethanol $(70 \%)$ and recentrifuged. The supernatant was discarded and the pellet was allowed to dry. The probe was then diluted in $20 \mu \mathrm{l}$ sterile $\mathrm{H}_{2} \mathrm{O}$. The quality of the probe was verified by electrophoresis in a $1 \%$ agarose gel. If no smear was observed and the size was as expected, the probe was considered to be ready for use. The quantity of RNA was evaluated by a Nanodrop (ND-1000 Spectrophotometer, Labtech) and adjusted to $150 \mathrm{ng} / \mu \mathrm{l}$ in hybridization buffer, then stored at $-20^{\circ} \mathrm{C}$ until use.

\section{In situ Hybridization}

Slides were allowed to thaw to room temperature (RT) for $2 \mathrm{~h}$. Then they were post-fixed on ice in $4 \%$ paraformaldehyde (diluted in PBS) for $10 \mathrm{~min}$ and rinsed in PBS. The hybridization buffer was composed of $50 \%$ deionized formamide, $10 \%$ dextran sulfate, $1-\mathrm{mg} / \mathrm{ml}$ yeast tRNA, $1 \times$ Denhardt's solution, and $1 \times$ salt solution $\left(0.195 \mathrm{M} \mathrm{NaCl}, 5 \mathrm{mM}\right.$ Tris pH 7.2, $5 \mathrm{mM} \mathrm{NaH}_{2} \mathrm{PO}_{4} \cdot 1 \mathrm{H}_{2} \mathrm{O}$, $5 \mathrm{mM} \mathrm{Na}_{2} \mathrm{HPO}_{4} \cdot 12 \mathrm{H}_{2} \mathrm{O}, 5 \mathrm{~mm}$ EDTA pH 8). The probe was diluted in hybridization buffer at a concentration of $1 \mu \mathrm{g} / \mathrm{ml}$. The probe mix was denatured by a 10 -min incubation at $70^{\circ} \mathrm{C}$ and placed on ice. An aliquot of $100 \mu \mathrm{l}$ was applied on each slide, which were covered by coverslips and allowed to hybridize overnight at $65^{\circ} \mathrm{C}$ in humidified chambers. The slides were then washed 2 times for $30 \mathrm{~min}$ at $65^{\circ} \mathrm{C}$ in $1 \times$ standard saline citrate (SSC), 50\% formamide, $0.1 \%$ Tween-20, and 2 times for $30 \mathrm{~min}$ at $\mathrm{RT}$ in MABT buffer ( $1 \times$ MAB (Maleic acid buffer): $0.5 \mathrm{M}$ maleic acid (Roche), $0.75 \mathrm{M} \mathrm{NaCl}, \mathrm{NaOH}$ to ph 7.5 plus $0.1 \%$ Tween-20).

Probe detection was performed using antibodies and reagents from Roche. Slides were incubated for $1 \mathrm{~h}$ at RT with a blocking solution (20\% goat serum, $2 \%$ blocking reagent in MABT). The anti-DIG antibody was diluted 1:2,500 in blocking solution, and $200 \mu \mathrm{l}$ was added to each slide, which were covered by Parafilm and incubated overnight at $4^{\circ} \mathrm{C}$. Slides were washed 5 times in MABT for $20 \mathrm{~min}$ and then 2 times for $10 \mathrm{~min}$ in NTMT buffer $\left(100 \mathrm{~mm} \mathrm{NaCl}, 100 \mathrm{~mm}\right.$ Tris- $\mathrm{HCl} \mathrm{pH}$ 9.5, $50 \mathrm{mM} \mathrm{MgCl}_{2} \cdot 6 \mathrm{H}_{2} \mathrm{O}$, $0.1 \%$ Tween-20). An aliquot of $200 \mu \mathrm{l}$ of freshly prepared staining solution $(3.5 \mu \mathrm{l}$ nitro-blue tetrazolium chloride (Roche), $3.5 \mu \mathrm{l}$ 5-bromo-4-chloro-3'-indolylphosphate p-toluidine salt (Roche) in NTMT buffer) was placed on each slide, covered by a Parafilm and incubated overnight in the dark at RT. The staining solution was changed every day and when signal was optimal the slides were rinsed 2 times during $5 \mathrm{~min}$ in NTMT buffer. The slides were further rinsed by PBS and water, allowed to dry overnight, and mounted in Coverquick 2000 mounting medium (Labonord).

\section{Results}

\section{Selection of Candidate Genes}

As described in the introduction section, 5 genes were selected on the basis of their involvement in rare human 
diseases and orodental anomalies (for an example, see fig. 1) [Vermeulen et al., 1994; Weeda et al., 1997; RuizPerez et al., 2000; Kondo et al., 2002; Courtois et al., 2003; McDonald et al., 2007; Vieira et al., 2007; Rutledge et al., 2010; Allanson et al., 2011]. Preliminary observation of in situ hybridization signals in the developing tooth buds and/or oral ectoderm of E14.5 mouse fetuses is shown in the EURExpress/GenePaint databases (http://www. eurexpress.org; http://www.genepaint.org/) [Diez-Roux et al., 2011]. A brief description of each gene is given hereafter, with table 1 providing additional information on the proteins encoded, mode of inheritance, and symptomatology of the corresponding syndromes or rare diseases.

Irf6 encodes an interferon regulatory transcription factor. It was recently reported that p63 and IRF6 interact epistatically in palatogenesis, and that IRF6 is a target of p63 in the midface [Moretti et al., 2010; Thomason et al., 2010]. Members of the IRF family are known to activate the canonical NF- $\kappa B$ pathway [Hiscott, 2007].

Nfkbia (formerly known as Ikba: NF- $\mathrm{BB}$ inhibitor $\alpha$ ) is a member of the NF- $\mathrm{BB}$ inhibitor family. Mutations in this gene were discovered in autosomal dominant anhidrotic ED with T-cell immunodeficiency [Courtois et al., 2003; Lopez-Granados et al., 2008].

Ercc3, the excision repair cross-complementing 3/xeroderma pigmentosum B (ERCC3/XPB) DNA helicase, a subunit of the transcription factor TFIIH complex, is also involved in the DNA nucleotide excision repair mechanism.

$E v c 2$ is a positive regulator of the Hedgehog signaling pathway, and encodes a cilium transmembrane protein located at the basal body of primary cilia. It is also found in the nucleus, where its function remains to be clarified [Blair et al., 2011].

Map2k1 (formerly known as Mek1 or Mapkk1), is a member of the dual specificity protein kinase family which acts as a mitogen-activated protein (MAP) kinase kinase and is involved in many cellular processes such as proliferation, differentiation, transcriptional regulation and development. Developmental syndromes involving dysregulation of the RAS/MAPK pathway are referred to as RASopathies [Rauen et al., 2010].

\section{In situ Hybridization Expression Analysis}

Tooth and Oral Cavity Development

Table 2 provides a summary of the various transcript distributions observed in developing tooth tissues, which are described below.

Irf6 transcripts were detected in the epithelial compartment of the teeth: at E12.5 in the oral ectoderm and

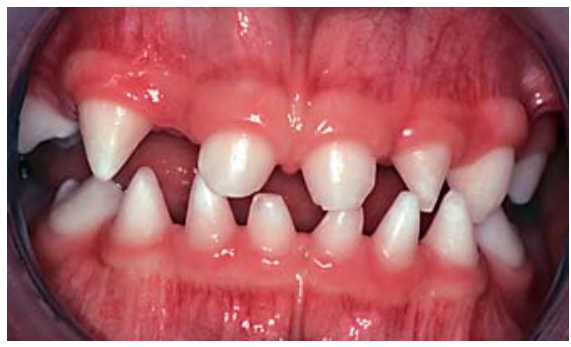

Fig. 1. An orodental phenotype observed in an ectodermal dysplasia (ED), here hypohidrotic ED shown as an example, includes missing teeth (hypodontia, oligodontia), microdontia and abnormalities of tooth shape (conical teeth). The anomalies of tooth number, shape and size are associated and represent a continuum of anomalies.

dental lamina (fig. 2A, B); at E14.5 throughout the whole enamel organ, especially in the future epithelial loop area (fig. 2C, D); at E16.5 in the outer dental epithelium, the stellate reticulum, and more intensely in the stratum intermedium and the epithelial loops (fig. 2E, F); and at E19.5 in the outer dental epithelium, the stratum intermedium, the preameloblasts, the inner dental epithelium and both epithelial loops (fig. 2G, H). Areas containing highly proliferative cells (such as the epithelial loops or stem cell niche) were strongly labeled.

The Nfkbia probe labeled the oral ectoderm and dental lamina at E12.5 (fig. 3A, B). At E14.5 the transcripts were scattered in the enamel organ of all teeth, with a particularly strong labeling of the enamel knot (fig. 3C, D). The epithelium lining the palatal shelves was labeled prior to contact (data not shown). At E16.5 at the bell stage, the epithelial loops, inner dental epithelium and outer dental epithelium were most prominently labeled (fig. 3E, F). At E19.5 the transcripts were localized in the inner and outer dental epithelium, in the preameloblast area and in the epithelial loops (for the second molars), as well as in odontoblasts (fig. 3G, H).

Ercc3 expression was detected in the oral ectoderm at E12.5 and E14.5 (as seen on cap stage lower incisors fig. $4 \mathrm{~A}$ and data not shown). Ercc3 was expressed in the enamel organ and more weakly in the mesenchyme both in molar and incisor at E14.5 (fig. 4A) and E16.5 (fig. 4B and data not shown). The in situ hybridization signal was quite faint and dotty. At E19.5 the labeling was clearly asymmetric and, for the incisors, was higher in the labial area within the epithelial loop and facing mesenchyme. The preameloblasts were also labeled (fig. 4C). The most differentiated epithelial cells were devoid of signal. At E19.5, the signal was visible both in the first 


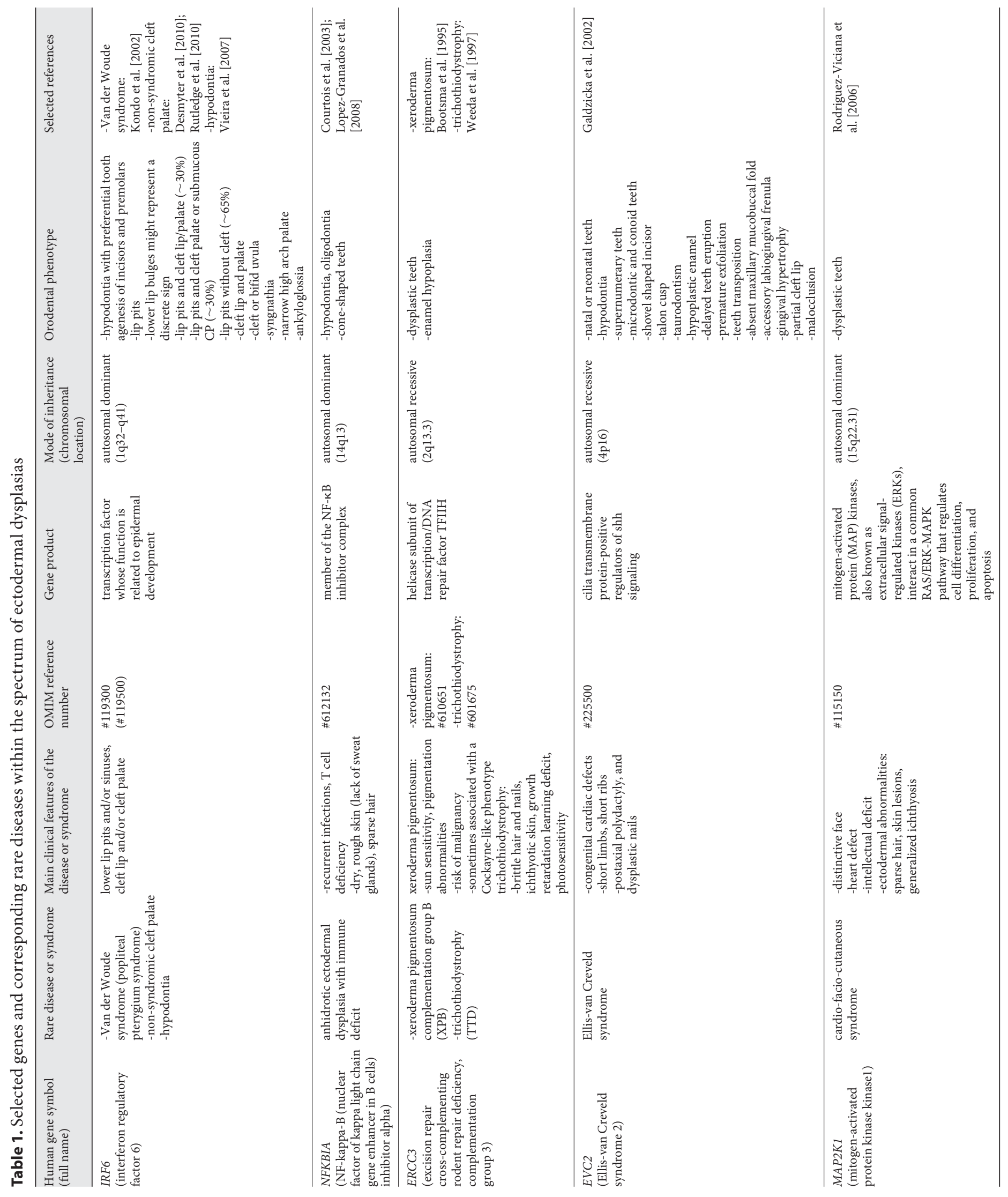


Table 2. Summary of the in situ hybridization data during odontogenesis

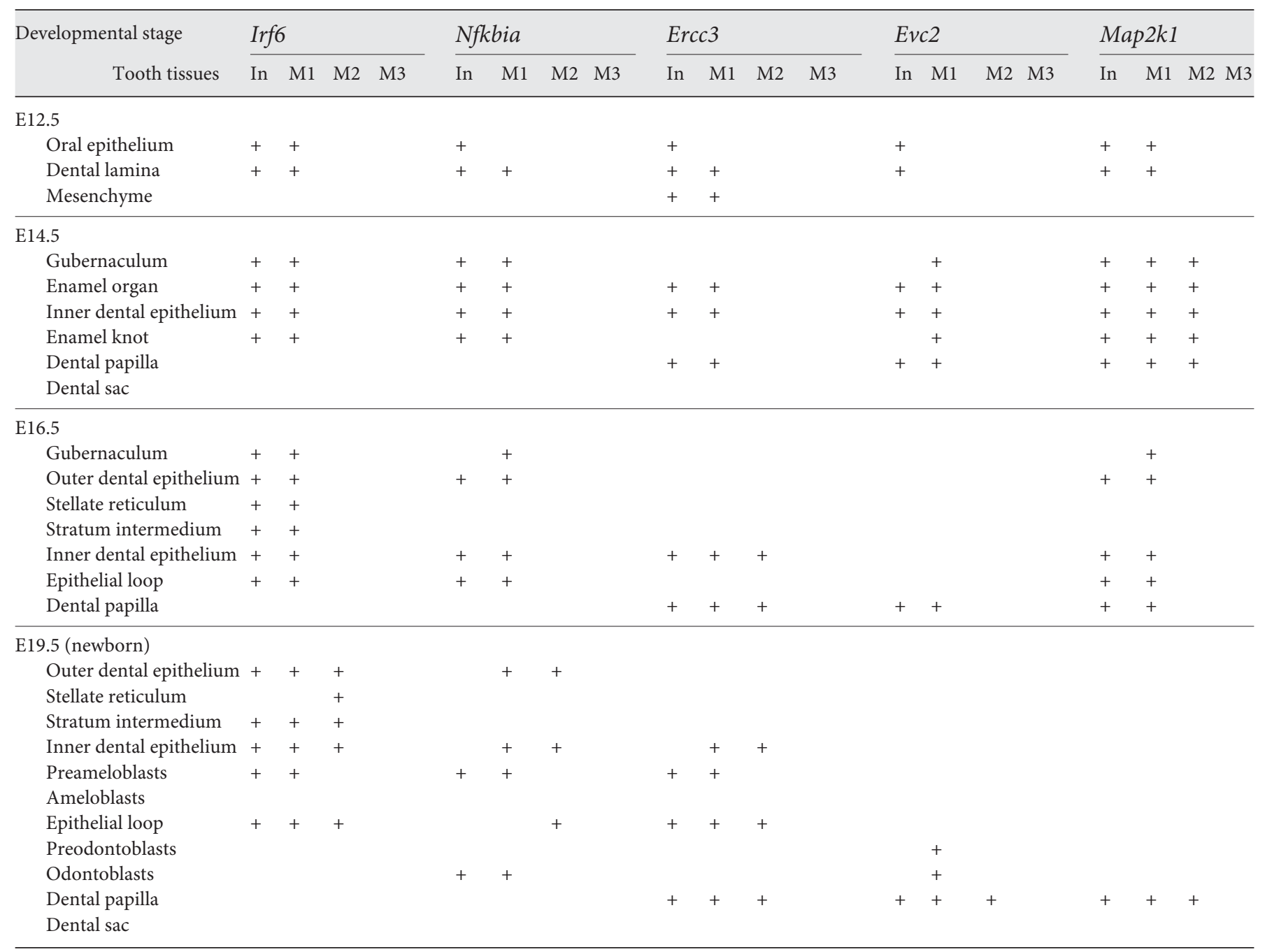

In = Incisor; M1 = first molar; M2 = second molar; M3 = third molar; + = indicates presence of signal.

and second molars in the inner dental epithelium, the preameloblasts and the epithelial loops (data not shown). In the second molars it was widespread in the mesenchyme whereas it was more focused to the base of the cusps and the area facing the epithelial loops for the first molars. In the inner dental epithelium the signal was clearly visible in the basal region of cells in contact with the basement membrane.

$E v c 2$ was expressed in the oral ectoderm and the dental lamina at E12.5 (data not shown). At E14.5 the signal was observed in the molar cap both in the enamel organ and within the ectomesenchyme (fig. 4D). The molar gubernaculum was also labeled. At E16.5 cartilaginous tissues including Meckel cartilage were strongly expressing this gene (data not shown). A faint signal was detected in the incisor and molar mesenchyme. At E19.5 the transcripts were detected in the mesenchyme and in the preodontoblast/odontoblast layers (data not shown).

Map $2 k 1$ was expressed in the oral ectoderm and the epithelial dental lamina at E12.5 (data not shown). The signal was then apparent both in the epithelial and mesenchymal compartments of the cap stage teeth at E14.5 (fig. 4E and data not shown). At E16.5, in addition to cartilaginous areas, the transcripts were detected in the mesenchyme and the epithelial inner, outer and loop areas for both the incisors and molars (fig. 4F and data not shown). At E19.5 the transcripts were mainly mesenchymal (fig. $4 \mathrm{G}$ ). 

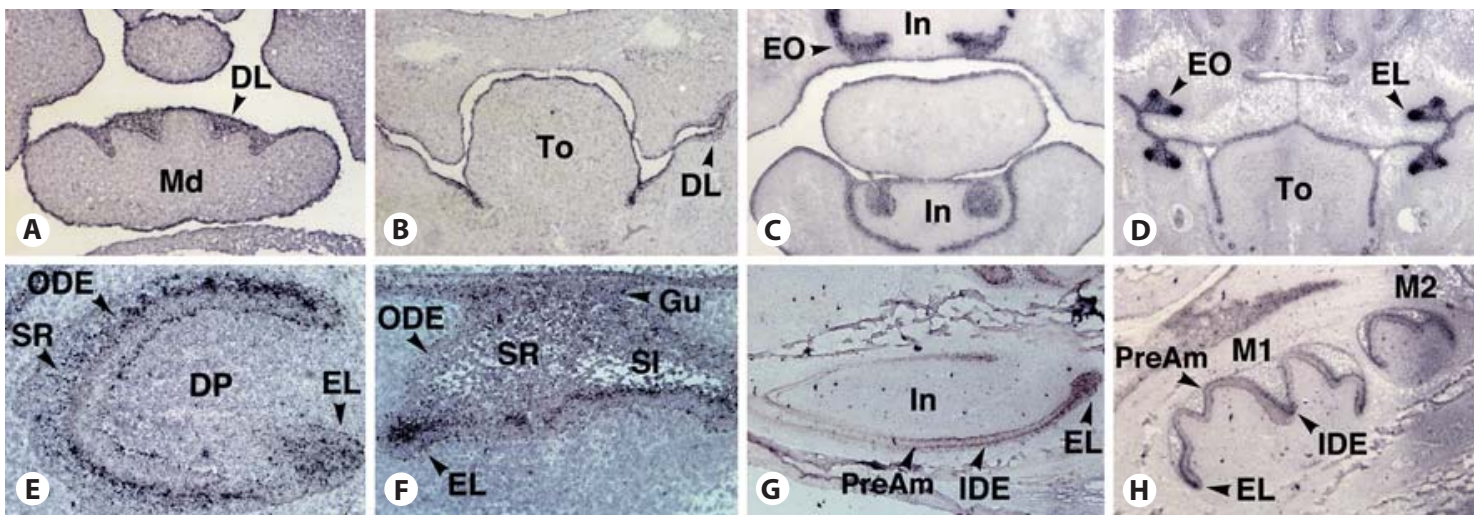

Fig. 2. In situ hybridization analysis of Irf6 gene expression in the developing teeth and oral cavity. Selected sections are shown at E12.5 (A mandible and incisor dental lamina; B palate, with vertical palatal shelves on each side of the tongue, and molar dental lamina), E14.5 (C lower and upper cap stage incisors; D palate and lower and upper cap stage first molars), E16.5 (E bell stage lower incisor; F mandibular first molar), and E19.5 (G lower incisor;
$\mathbf{H}$ first and second molars). All section planes are coronal (frontal), except for E-H (sagittal). DL = Dental lamina, DP = dental papilla, $\mathrm{EL}=$ epithelial loop, $\mathrm{EO}=$ enamel organ, $\mathrm{Gu}$ = gubernaculum, IDE = inner dental epithelium, In = incisor, $\mathrm{M} 1$ = first molar, M2 = second molar, $\mathrm{Md}=$ mandible, $\mathrm{ODE}=$ outer dental epithelium, PreAm = preameloblasts, $\mathrm{SI}=$ stratum intermedium, $\mathrm{SR}=$ stellate reticulum, To $=$ tongue.
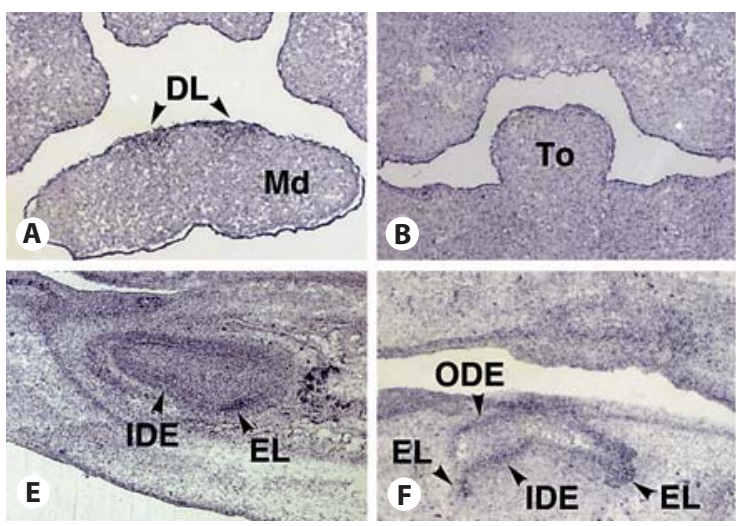

\section{B}

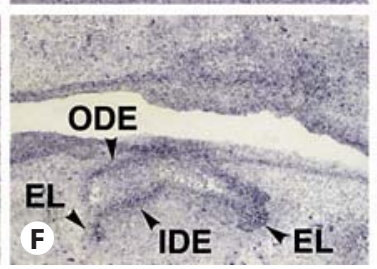

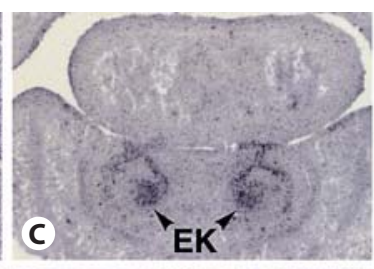

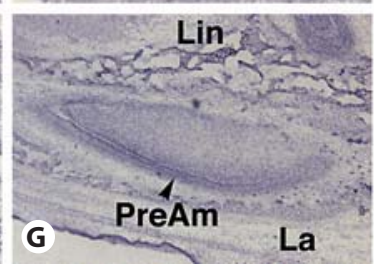

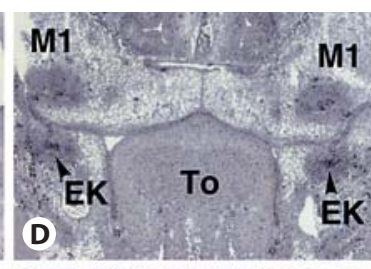

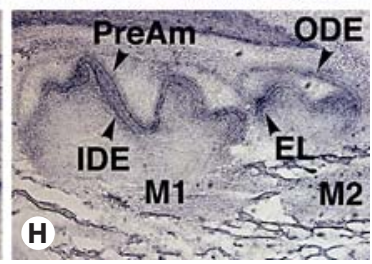

Fig. 3. In situ hybridization analysis of Nfkbia expression in the developing teeth and oral cavity. The selected sections show the mandibular incisor dental lamina (A), posterior tongue/pharyngeal region and molar dental lamina (B) at E12.5, the lower incisors (C) and the first molar caps (D) at E14.5, the lower incisor (E) and the first mandibular molar (F) at E16.5, and the lower incisor
(G) and first and second molars (H) at E19.5. All section planes are coronal, except for $\mathbf{E}-\mathbf{H}$, which are sagittal. DL = Dental lamina, $\mathrm{EK}=$ enamel knot, EL = epithelial loop, IDE = inner dental epithelium, La = labial, Lin = lingual, M1 = first molar, M2 = second molar, $\mathrm{Md}=$ mandible, $\mathrm{ODE}=$ outer dental epithelium, PreAm = preameloblasts, To $=$ tongue.
Salivary Glands and Vibrissae

The expression patterns of Irf6, Nfkbia, Ercc3, Evc2, and Map2k1 are further illustrated in 2 organs in which specialized ectoderm-derived tissues are developing, the salivary (submandibular) glands and the vibrissae follicles (fig. 5). With the exception of Evc2, all genes displayed distinct expression in the epithelial cell component of the developing salivary glands (fig. 5A-E). Irf6 and Map2k1 were particularly strongly expressed in the epithelial layer of the vibrissae follicle shafts whereas Nfkbia displayed weaker discontinuous labeling and Ercc3 as well as Evc2 no obvious expression in this epithelial compartment (fig. 5F-J). 

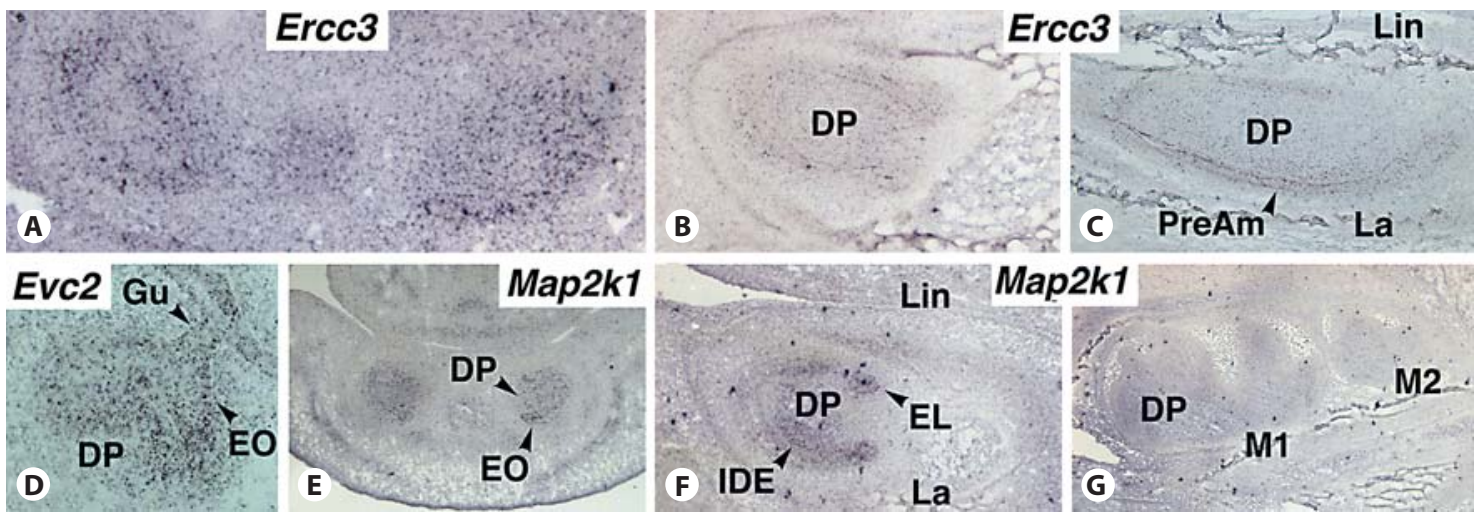

Fig. 4. In situ hybridization expression patterns observed for Ercc3 (A-C), Evc2 (D) and Map2k1 (E-G). The selected sections show the lower cap stage incisors (A, E) and lower first molar (D) at E14.5, the mandibular incisor (B, F) at E16.5, the lower incisor (C) and first and second molars (G) at E19.5. All section planes are

sagittal, except for A, B, E, which are frontal. DP = Dental papilla, $\mathrm{EL}=$ epithelial loop, $\mathrm{EO}=$ enamel organ, $\mathrm{Gu}$ = gubernaculum, $\mathrm{IDE}=$ inner dental epithelium, PreAm = preameloblasts, $\mathrm{La}=$ labial, Lin = lingual, $\mathrm{M} 1$ = first molar, $\mathrm{M} 2$ = second molar.
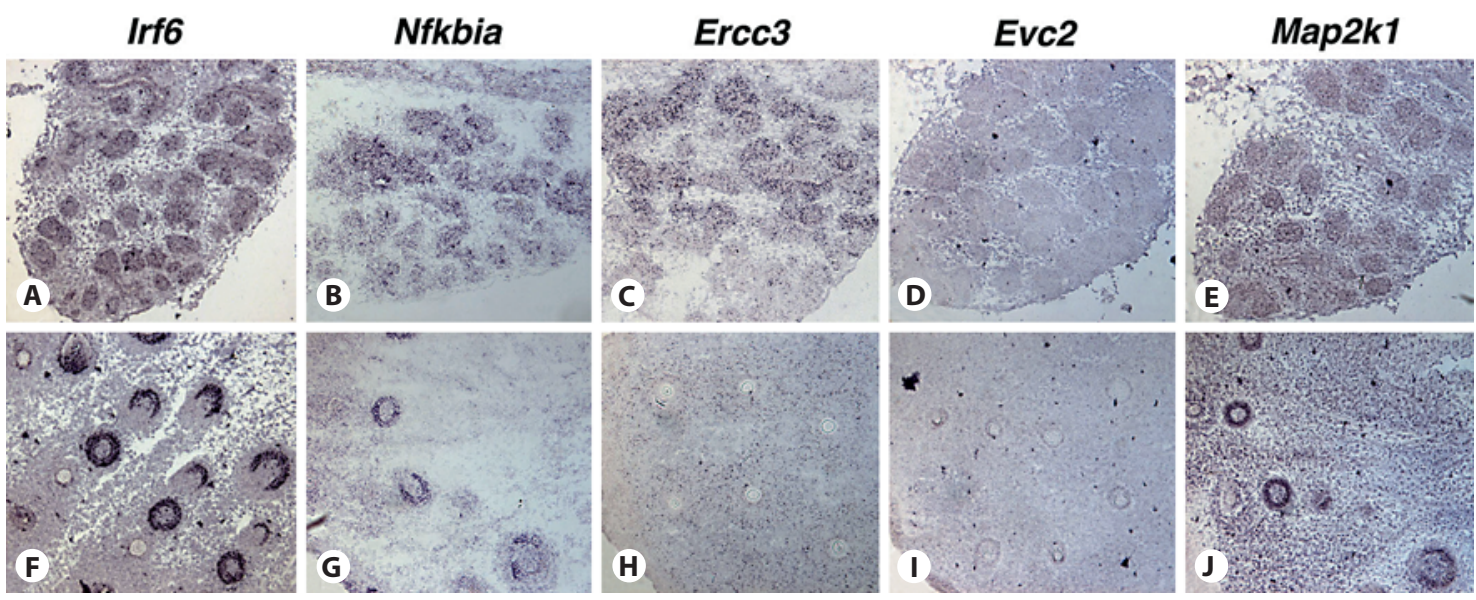

Fig. 5. Expression of ED-related genes in the E16.5 developing submandibular salivary gland (A-E), and vibrissae follicles (F-J). In all cases where expression is detected $(\mathbf{A}-\mathbf{C}, \mathbf{E}-\mathbf{G}, \mathbf{J})$, it is selectively seen in the epithelial compartment.

\section{Discussion}

Tooth development is embedded within craniofacial development. It originates from pluripotent cephalic neural crest cells which migrate towards the first pharyngeal arch, triggering in combination with mesodermal cells the development of many craniofacial structures [Cobourne and Mitsiadis, 2006; Knight and Schilling, 2006; Noden and Schneider, 2006]. Odontogenesis leads to specific crown and root morphogenesis for each type of tooth (incisors and molar for the mouse), to enamel organ histomorphogenesis and to terminal cytodifferentiation of odontoblasts, ameloblasts and cementoblasts. Evolutionary study of mammals is often focused on detailed analysis of tooth shapes. Molecular patterning may influence dental evolution via differences in gene expressions correlated with morphological variations [Jernvall et al., 2000; Salazar-Ciudad and Jernvall, 2002; Plikus et al., 2005]. The continuous and progressive stages of odontogenesis have classically been divided into the dental lamina, placode, bud, cap and bell stages, root formation and tooth eruption. Tooth development is a dynamic pro- 
cess mediated by epithelio-mesenchymal interactions between ectomesenchymal cells originating from cephalic neural crest cells and the first pharyngeal arch ectoderm [Peters and Balling, 1999; Thesleff and Aberg, 1999; Tucker and Sharpe, 1999; Thesleff, 2003a; Tucker and Sharpe, 2004]. These cells contribute to the formation of the dental mesenchyme, the dental pulp, odontoblasts, dentine matrix, cement and periodontium [Chai et al., 2000; Miletich and Sharpe, 2004]. Extracellular matrix (i.e. basement membrane, predentine, dentine) participates in odontogenesis either as a substrate for interaction with receptors of the plasma membrane, or as a putative reservoir of endocrine or paracrine factors like peptide growth factors. Tooth morphogenesis is under strict genetic control and the participating genes are being discovered at an increasing speed. By 2008, more than 300 of these genes had been listed in the database created by P. Nieminen (Helsinki University, Finland) gathering expression patterns at various stages of odontogenesis from worldwide laboratories (http://bite-it.helsinki.fi) [Nieminen et al., 1998].

Developmental dental anomalies may exist in isolation or may be associated with extraoral clinical manifestations in syndromes, and can be of genetic origin or due to the action of teratogens [Alaluusua et al., 1999; Berdal, 2003; Koch, 2003; Weerheijm, 2003; Alaluusua, 2006; Alaluusua and Lukinmaa, 2006]. They are correlated to specific genetic and developmental biology events [BlochZupan, 2004; Bloch-Zupan et al., 2012] such as the embryonic origins of dental cells, the patterning of the dentition, the defined location of tooth development, tooth identity, specific morphogenesis, histogenesis, terminal differentiation of odontoblasts and ameloblasts, dentine and enamel matrix synthesis followed by mineralization, root and periodontium formation and eruption of teeth [Salazar-Ciudad and Jernvall, 2002; Thesleff, 2003a, b, 2006]. Any interference with these developmental processes can lead to clinical anomalies and defects [Thesleff, 2000, 2006; Aldred et al., 2003; MacDougall, 2003] and some may even lead to tumors from dental epithelial cells [Papagerakis et al., 1999]. EDs are disorders characterized by alterations in 2 or more ectodermal structures affected in the following decreasing order of frequency: hair, teeth, nails, sweat glands, salivary glands and any other ectodermal appendage [Visinoni et al., 2009]. So far, identification of a wide variety of genes has led to the molecular characterization of around 30\% of EDs and to a reconsideration of their clinical classification. The genes selected in the present study are involved in various rare diseases belonging to the ED spectrum: IRF6 in Van der Woude syndrome [Kondo et al., 2002], non-syndromic cleft lip/palate [Vieira et al., 2007; Desmyter et al., 2010; Rutledge et al., 2010], hypodontia [Vieira et al., 2007]; NFKBIA in ED with immune deficit [Courtois et al., 2003; Lopez-Granados et al., 2008]; ERCC3 in xeroderma pigmentosum [Bootsma et al., 1995] and trichothiodystrophy [Weeda et al., 1997]; EVC2 in Ellis-van Creveld syndrome [Galdzicka et al., 2002]; MAP2K1 [RodriguezViciana et al., 2006] in cardiofaciocutaneous syndrome.

While the same genes are indeed involved in different diseases with overlapping phenotypes, it is also interesting to note that mutations in different genes may account for similar diseases. Cardiofaciocutaneous syndrome, for example, is caused by gain of function mutations in $B R A F$ (7q34), KRAS2 (12p12.1), MEK2 (7q32) and MAP2K1 (15q21) [Allanson et al., 2011]; Ellis-van Creveld syndrome is caused by mutations in EVC and EVC2 (4p16.2) [Ruiz-Perez et al., 2003].

Our in situ hybridization expression data confirmed the transcription of the selected murine genes in different tissues/organs of ectodermal origin (teeth, salivary glands, vibrissae). However, Nfkbia, Ercc3, Evc2, and Map2k1 signals were also present in the ectomesenchymal compartments of the tooth germs. Indeed, EDs are groups of conditions presenting similar ectodermal signs, but the associated defects may primarily concern mesenchymal structures, for example bone in Ellis-van Creveld syndrome. Expression of Irf6 was previously described [Kondo et al., 2002; Knight et al., 2005; Blackburn et al., 2012] as occurring in the ectoderm covering the facial processes during the formation of the lip, the primary palate, and the secondary palate from E14.5 to E15 mouse embryos. Recently, information was provided about the localization of Irf6 transcripts between E10.5 and E18.5 during odontogenesis [Blackburn et al., 2012]. No precise description at the tissular level (outer dental epithelium, stratum intermedium, inner dental epithelium, preameloblasts) was given, however. For example the strong signal and localization within the future epithelial loop area of the cap, then bell stage teeth (i.e. the proliferating area), were not described.

MAP2K1 immunolocalization was described in human third molar tooth germs enucleated for orthodontic reasons at the early crown mineralization stage. Strong reactivity was observed in inner dental epithelium, and weak to moderate staining was visible in outer dental epithelium, stratum intermedium and stellate reticulum [Kumamoto et al., 2004]. These results are in agreement with the expression pattern described for Map2k1 in the present study except for the localization within the stel- 
late reticulum and stratum intermedium sometimes difficult to assess.

The expression patterns of Nfkbia, Ercc3 and Evc2 during odontogenesis had never been reported previously. The expression patterns described herein are consistent in timing and localization with the known dental anomalies (hypodontia/oligodontia, smaller and conical teeth, enamel hypoplasia) occurring in patients [Clauss et al., 2008; Gros et al., 2010]. Disruption of molecular/biological events at early stages of odontogenesis (dental lamina, transition bud to cap stage) are linked to missing teeth, at the cap stage to anomalies of tooth shape and size, at the bell stage and terminal cytodifferentiation with anomalies of tooth structure (dentine and enamel). It is also interesting to notice that cleft lip and palate are symptoms present in the clinical synopsis of Ellis-van Creveld and Van der Woude syndromes and that the corresponding genes ( $E v c 2$ and $I r f 6$ ) are expressed in the palatal medial epithelial edge and seam (data not shown).

Mouse models generated by targeted gene mutations often mimick the phenotypes encountered in corresponding rare human diseases [Fleischmannova et al., 2008]. The Ercc3 knock-in mice [Andressoo et al., 2009] recapitulate the UV sensitivity typical for xeroderma pigmentosum, but fail to show overt Cockayne syndrome features, i.e. no observation or mention of an orodental phenotype was described for the mutant mice. Evc nullmutant mice develop an EVC-like syndrome, including short ribs, short limbs and dental abnormalities [RuizPerez et al., 2007]. Mutants showed small dysplastic incisors, and conical lower molars. The size of the first molar was reduced, and enamel defects were visible. Null-mutant mice for Irf6 have abnormal skin, limb and craniofacial development [Ingraham et al., 2006]. Histological and gene expression analyses indicate that the primary defect is in keratinocyte differentiation and proliferation. The cleft palate 1 (Clft1) mutant mouse also displays a mutation in Irf6 (Van der Woude syndrome mutation) [Ingraham et al., 2006; Stottmann et al., 2010]. The mandible in the Irf6 mutant was smaller with a narrower angle than in the wild-type, and the snout was also shorter with cleft palate [Ingraham et al., 2006]. Protruding incisors were described in Irf6 mutant mice, pointing toward an important role of IRF6 in tooth epithelial invagination [Blackburn et al., 2012]. The disruption of the murine Map2 $k 1$ gene leads to an embryonically lethal phenotype at mid-gestation from an abnormal placenta development and vascularization [Bissonauth et al., 2006]. Ikbia-deficient mice show skin defects and die at day 9 post-natally with severe widespread dermatitis and increased levels of
TNF- $\alpha$ mRNA in the skin [Klement et al., 1996]. These mice develop a severe hematological disorder [Rupec et al., 2005]; however, no features reminiscent of ED and dental abnormalities observed in human patients with NFKBIA mutations were described in mice.

\section{Conclusions}

Orodental anomalies of transgenic mouse models are often insufficiently described, thus making it difficult to fully compare mouse and human disease phenotypes. However, the mouse orodental anomalies quite frequently reflect the human counterpart malformations with regard to the clinical synopsis of syndromes, confirming the informative role of these models to study tooth development and anomalies. This study described the expression pattern of murine homologs of human genes involved in tooth development and disease, focusing on the ED spectrum. It reinforces the utility of translational approaches in development and medicine to gain understanding of the molecular events underlying the clinical manifestations, especially the orodental anomalies accompanying these rare diseases.

\section{Acknowledgements}

This work was supported by grants from the University of Strasbourg, the Hôpitaux Universitaires de Strasbourg (API, 2009-2012, 'Development of the oral cavity: from gene to clinical phenotype in human') and IFRO (Institut Français pour la Recherche Odontologique), and by institutional funds from the Centre National de la Recherche Scientifique (CNRS) and Institut National de la Santé et de la Recherche Médicale (INSERM). V.L.-H. was the recipient of $\mathrm{PhD}$ fellowship from the Ministère Français de la Recherche.

References

Alaluusua S: Amoxicillin may be a cause of enamel hypomineralization [in Finnish]. Duodecim 122:491-492 (2006).

- Alaluusua S, Lukinmaa PL: Developmental dental toxicity of dioxin and related compounds - a review. Int Dent J 56:323-331 (2006).

- Alaluusua S, Lukinmaa PL, Torppa J, Tuomisto J, Vartiainen T: Developing teeth as biomarker of dioxin exposure. Lancet 353:206 (1999).

-Aldred MJ, Savarirayan R, Crawford PJ: Amelogenesis imperfecta: a classification and catalogue for the 21st century. Oral Dis 9:19-23 (2003). 
Allanson JE, Anneren G, Aoki Y, Armour CM, Desmyter L, Ghassibe M, Revencu N, Boute O, Bondeson ML, et al: Cardio-facio-cutaneous syndrome: does genotype predict phenotype? Am J Med Genet C Semin Med Genet 157:129-135 (2011).

-Andressoo JO, Weeda G, de Wit J, Mitchell JR, Beems RB, et al: An Xpb mouse model for combined xeroderma pigmentosum and Cockayne syndrome reveals progeroid features upon further attenuation of DNA repair. Mol Cell Biol 29:1276-1290 (2009).

Aymé S: Orphanet, an information site on rare diseases [in French]. Soins 46-47 (2003).

-Aymé S, Urbero B, Oziel D, Lecouturier E, Biscarat AC: Information on rare diseases: the Orphanet project [in French]. Rev Med Interne 19(suppl 3):376S-377S (1998).

Berdal A: Gene/environment relations in the development of tooth anomalies [in French]. Arch Pediatr 10(suppl 1):16s-18s (2003).

Bissonauth V, Roy S, Gravel M, Guillemette S, Charron J: Requirement for Map2k1 (Mek1) in extra-embryonic ectoderm during placentogenesis. Development 133:3429-3440 (2006).

-Blackburn J, Ohazama A, Kawasaki K, OtsukaTanaka Y, Liu B, et al: The role of Irf6 in tooth epithelial invagination. Dev Biol 365:61-70 (2012).

Blair HJ, Tompson S, Liu YN, Campbell J, MacArthur K, et al: Evc2 is a positive modulator of Hedgehog signalling that interacts with Evc at the cilia membrane and is also found in the nucleus. BMC Biol 9:14 (2011).

Bloch-Zupan A: Odonto-génétique: une nouvelle facette de notre profession! Le Chirurgien Dentiste de France 1182:77-86 (2004).

Bloch-Zupan A, Sedano H, Scully C: Dento/Oro/ Craniofacial Anomalies and Genetics. (Elsevier Inc., London 2012).

Bootsma D, Weeda G, Vermeulen W, van Vuuren H, Troelstra C, et al: Nucleotide excision repair syndromes: molecular basis and clinical symptoms. Philos Trans R Soc Lond B Biol Sci 347:75-81 (1995).

Chai Y, Jiang X, Ito Y, Bringas P Jr, Han J, et al: Fate of the mammalian cranial neural crest during tooth and mandibular morphogenesis. Development 127:1671-1679 (2000).

-Clauss F, Maniere MC, Obry F, Waltmann E, Hadj-Rabia S, et al: Dento-craniofacial phenotypes and underlying molecular mechanisms in hypohidrotic ectodermal dysplasia (HED): a review. J Dent Res 87:1089-1099 (2008).

Cobourne MT, Mitsiadis T: Neural crest cells and patterning of the mammalian dentition. J Exp Zool B Mol Dev Evol 306:251-260 (2006).

Courtois G, Smahi A, Reichenbach J, Doffinger $\mathrm{R}$, Cancrini $\mathrm{C}$, et al: A hypermorphic IkappaBalpha mutation is associated with autosomal dominant anhidrotic ectodermal dysplasia and $\mathrm{T}$ cell immunodeficiency. J Clin Invest 112:1108-1115 (2003). Lees M, et al: IRF6 screening of syndromic and a priori non-syndromic cleft lip and palate patients: identification of a new type of minor VWS sign. Mol Syndromol 1:67-74 (2010).

Diez-Roux G, Banfi S, Sultan M, Geffers L, Anand S, et al: A high-resolution anatomical atlas of the transcriptome in the mouse embryo. PLoS Biol 9:e1000582 (2011).

-Fleischmannova J, Matalova E, Tucker AS, Sharpe PT: Mouse models of tooth abnormalities. Eur J Oral Sci 116:1-10 (2008).

Galdzicka M, Patnala S, Hirshman MG, Cai JF, Nitowsky H, et al: A new gene, EVC2, is mutated in Ellis-van Creveld syndrome. Mol Genet Metab 77:291-295 (2002).

Gorlin RJ, Cohen MM, Hennekam RC: Syndromes of the Head and Neck (Oxford University Press, USA 2001).

Gros CI, Clauss F, Obry F, Maniere MC, Schmittbuhl M: Quantification of taurodontism: interests in the early diagnosis of hypohidrotic ectodermal dysplasia. Oral Dis 16:292-298 (2010).

Hennekam RC, Krantz I, Allanson J: Gorlin's Syndromes of the Head and Neck (Oxford University Press, USA 2010).

Hiscott J: Convergence of the NF-kappaB and IRF pathways in the regulation of the innate antiviral response. Cytokine Growth Factor Rev 18:483-490 (2007).

- Ingraham CR, Kinoshita A, Kondo S, Yang B, Sajan S, et al: Abnormal skin, limb and craniofacial morphogenesis in mice deficient for interferon regulatory factor 6 (Irf6). Nat Genet 38:1335-1340 (2006).

Jernvall J, Keranen SV, Thesleff I: From the cover: evolutionary modification of development in mammalian teeth: quantifying gene expression patterns and topography. Proc Natl Acad Sci USA 97:14444-14448 (2000).

Klement JF, Rice NR, Car BD, Abbondanzo SJ, Powers GD, et al: IkappaBalpha deficiency results in a sustained NF-kappaB response and severe widespread dermatitis in mice. Mol Cell Biol 16:2341-2349 (1996).

Knight AS, Schutte BC, Jiang R, Dixon MJ: Developmental expression analysis of the mouse and chick orthologues of IRF6: the gene mutated in Van der Woude syndrome. Dev Dyn 235:1441-1447 (2005).

Knight RD, Schilling TF: Cranial neural crest and development of the head skeleton. Adv Exp Med Biol 589:120-133 (2006).

Koch G: Prevalence of enamel mineralisation disturbances in an area with 1-1.2 ppm F in drinking water. Review and summary of a report published in Sweden in 1981. Eur J Paediatr Dent 4:127-128 (2003).

Kondo S, Schutte BC, Richardson RJ, Bjork BC, Knight AS, et al: Mutations in IRF6 cause Van der Woude and popliteal pterygium syndromes. Nat Genet 32:285-289 (2002).
Kumamoto H, Takahashi N, Ooya K: K-Ras gene status and expression of Ras/mitogen-activated protein kinase (MAPK) signaling molecules in ameloblastomas. J Oral Pathol Med 33:360-367 (2004).

Lopez-Granados E, Keenan JE, Kinney MC, Leo $\mathrm{H}$, Jain N, et al: A novel mutation in NFK$\mathrm{BIA} / \mathrm{IKBA}$ results in a degradation-resistant $\mathrm{N}$-truncated protein and is associated with ectodermal dysplasia with immunodeficiency. Hum Mutat 29:861-868 (2008).

MacDougall M: Dental structural diseases mapping to human chromosome $4 \mathrm{q} 21$. Connect Tissue Res 44(suppl 1):285-291 (2003).

-McDonald DR, Mooster JL, Reddy M, Bawle E, Secord E, Geha RS: Heterozygous N-terminal deletion of IkappaBalpha results in functional nuclear factor kappaB haploinsufficiency, ectodermal dysplasia, and immune deficiency. J Allergy Clin Immunol 120:900907 (2007).

Miletich I, Sharpe PT: Neural crest contribution to mammalian tooth formation. Birth Defects Res C Embryo Today 72:200-212 (2004).

Moretti F, Marinari B, Lo Iacono N, Botti E, Giunta A, et al: A regulatory feedback loop involving p63 and IRF6 links the pathogenesis of 2 genetically different human ectodermal dysplasias. J Clin Invest 120:1570-1577 (2010).

-Nieminen P, Pekkanen M, Aberg T, Thesleff I: A graphical WWW-database on gene expression in tooth. Eur J Oral Sci 106(suppl 1):7-11 (1998).

Noden DM, Schneider RA: Neural crest cells and the community of plan for craniofacial development: historical debates and current perspectives. Adv Exp Med Biol 589:1-23 (2006).

Papagerakis P, Peuchmaur M, Hotton D, Ferkdadji L, Delmas P, et al: Aberrant gene expression in epithelial cells of mixed odontogenic tumors. J Dent Res 78:20-30 (1999).

Peters H, Balling R: Teeth. Where and how to make them. Trends Genet 15:59-65 (1999).

Plikus MV, Zeichner-David M, Mayer JA, Reyna J, Bringas P, et al: Morphoregulation of teeth: modulating the number, size, shape and differentiation by tuning Bmp activity. Evol Dev 7:440-457 (2005).

-Rauen KA, Schoyer L, McCormick F, Lin AE, Allanson JE, et al: Proceedings from the 2009 genetic syndromes of the Ras/MAPK pathway: from bedside to bench and back. Am J Med Genet A 152A:4-24 (2010).

Rodriguez-Viciana P, Tetsu O, Tidyman WE, Estep AL, Conger BA, et al: Germline mutations in genes within the MAPK pathway cause cardio-facio-cutaneous syndrome. Science 311:1287-1290 (2006).

Ruiz-Perez VL, Ide SE, Strom TM, Lorenz B, Wilson D, et al: Mutations in a new gene in Ellis-van Creveld syndrome and Weyers acrodental dysostosis. Nat Genet 24:283-286 (2000). 
Ruiz-Perez VL, Tompson SW, Blair HJ, Espinoza-Valdez C, Lapunzina P, et al: Mutations in two nonhomologous genes in a head-to-head configuration cause Ellis-van Creveld syndrome. Am J Hum Genet 72:728-732 (2003).

Ruiz-Perez VL, Blair HJ, Rodriguez-Andres ME, Blanco MJ, Wilson A, et al: Evc is a positive mediator of Ihh-regulated bone growth that localises at the base of chondrocyte cilia. Development 134:2903-2912 (2007).

Rupec RA, Jundt F, Rebholz B, Eckelt B, Weindl $G$, et al: Stroma-mediated dysregulation of myelopoiesis in mice lacking I kappa B alpha. Immunity 22:479-491 (2005).

- Rutledge KD, Barger C, Grant JH, Robin NH IRF6 mutations in mixed isolated familial clefting. Am J Med Genet A 152A:3107-3109 (2010).

-Salazar-Ciudad I, Jernvall J: A gene network model accounting for development and evolution of mammalian teeth. Proc Natl Acad Sci USA 99:8116-8120 (2002).

Stottmann RW, Bjork BC, Doyle JB, Beier DR: Identification of a Van der Woude syndrome mutation in the cleft palate 1 mutant mouse. Genesis 48:303-308 (2010).
Thesleff I: Genetic basis of tooth development and dental defects. Acta Odontol Scand 58: 191-194 (2000).

- Thesleff I: Epithelial-mesenchymal signalling regulating tooth morphogenesis. J Cell Sci 116:1647-1648 (2003a).

Thesleff I: Developmental biology and building a tooth. Quintessence Int 34:613-620 (2003b).

Thesleff I: The genetic basis of tooth development and dental defects. Am J Med Genet A 140:2530-2535 (2006).

- Thesleff I, Aberg T: Molecular regulation of tooth development. Bone 25:123-125 (1999).

Thomason HA, Zhou H, Kouwenhoven EN Dotto GP, Restivo G, et al: Cooperation between the transcription factors p63 and IRF6 is essential to prevent cleft palate in mice. J Clin Invest 120:1561-1569 (2010)

Tucker A, Sharpe P: The cutting-edge of mammalian development; how the embryo makes teeth. Nat Rev Genet 5:499-508 (2004).

Tucker AS, Sharpe PT: Molecular genetics of tooth morphogenesis and patterning: the right shape in the right place. J Dent Res 78: 826-834 (1999).
Vermeulen W, Scott RJ, Rodgers S, Muller HJ, Cole J, et al: Clinical heterogeneity within xeroderma pigmentosum associated with mutations in the DNA repair and transcription gene ERCC3. Am J Hum Genet 54:191200 (1994).

Vieira AR, Modesto A, Meira R, Barbosa AR, Lidral AC, Murray JC: Interferon regulatory factor 6 (IRF6) and fibroblast growth factor receptor 1 (FGFR1) contribute to human tooth agenesis. Am J Med Genet A 143:538545 (2007).

Visinoni AF, Lisboa-Costa T, Pagnan NA, Chautard-Freire-Maia EA: Ectodermal dysplasias: clinical and molecular review. Am J Med Genet A 149A:1980-2002 (2009).

-Weeda G, Eveno E, Donker I, Vermeulen W, Chevallier-Lagente $\mathrm{O}$, et al: A mutation in the $\mathrm{XPB} / \mathrm{ERCC} 3 \mathrm{DNA}$ repair transcription gene, associated with trichothiodystrophy. Am J Hum Genet 60:320-329 (1997).

-Weerheijm KL: Molar incisor hypomineralisation (MIH). Eur J Paediatr Dent 4:114-120 (2003). 